\title{
Transparent science
}

\section{Nature adopts new guidelines asking authors to disclose potential conflicts of interest}

$\mathrm{T}_{\mathrm{r} m}$ moment. An information through the vast reaches of the Internet has exposed science, medicine, law, religion and politics to intense public scrutiny. And this is no bad thing. An informed society is one that can reach decisions from a sound ethical and knowledgeable base. But the internal confines of the scientific community have felt somewhat immune to this trenddespite being increasingly held accountable by the public in the wake of the BSE crisis and the debate around genetically modified foods-believing itself to be sufficiently open.

In an ideal world, science is objective: the results of an experiment should be evaluated without massaging the data or manipulating them in any way. However, whether consciously or subconsciously, the danger is that these data may sometimes be interpreted in a certain, more favourable, light. With private funding of basic research on the increase, potential conflicts of interest are becoming more

With private funding of basic research on the increase, potential conflicts of interest are becoming more frequent

trequent and scientists may have more than their reputations at stake when making their results public.

To make such conflicts more transparent and open to the judgement of others, many scientific journals have the policy of asking their authors to voluntarily disclose any conflicts of interest that may have affected their work. Nature is the most recent amongst these to have adopted this stance, and with such a highprofile journal highlighting the potential problem, it could be that others will soon follow suit. 'We do not see that these networks between industry and academic research are a bigger problem and we also did not need to fill any gaps in the system, but we think that this is a step towards more transparency,' Philip Campbell, Nature's editor-in-chief, explained. 'I find transparency especially important when political decisions are based on published scientific data.'

For potential investors, the life sciences kinds of research fields have long asked for this information. I cannot recall seeing any negative influences in basic research yet, but I believe statements of possible conflicts of interest are of no harm,' Campbell said.

A recently published survey conducted in 1997 by Sheldon Krimsky of Tufts University, MA, and Leslie Rothenburg, UCLA, revealed that $16 \%$ of 1396 highly ranked scientific and biomedical journals

The startling part of the Krimsky \& Rothenburg survey is that less than $1 \%$ of articles published in scientific journals in 1997 contained a disclosure statement

promise high returns both immediately and in the long term. In the rush to exploit this potential goldmine, a number of recent trends have emerged: companies of all sizes have developed an interest in basic research in this field and often support projects at both academic and research institutes; researchers are increasingly being asked by their academic institutions or financial sources to patent the results of their work, and university professors are starting their own biotechnology companies. While often making sound business sense, the pressures associated with these corporateacademic collaborations could lead to conflicts between the interests of scientific research and the rules of economics. To state these associations as part of a publication is not to imply scientific misconduct, but rather to make science more transparent and accountable both within its own community and to the public.

Certainly in applied research, where public funding bodies often involve private partners in research projects right from the start, this is nothing new. 'Many journals that publish results from these ask their authors to declare any potential conflict of interest. But the more startling part of the survey is that less than $1 \%$ of articles published in those journals that year actually contained any such statements. It is difficult to believe that this is a true reflection of funding sources, but while disclosure remains a voluntary process, this low response is likely to prevail.

However, Nature's new policy may also help to kick-start a trend of increased transparency, and, as of October 2001, they request that authors of scientific papers supply information on three issues:

Funding: Research support (including salaries, equipment, supplies, reimbursement for attending symposia and other expenses) by organisations that may gain or lose financially through publication of the paper.

Employment: Recent (i.e. while engaged in the research project), present or anticipated employment by any organisation that may gain or lose financially through publication of the paper.

Personal financial interests: Stocks or shares in companies that may gain or lose 


\section{analysis}

financially through publication; consultation fees or other forms of remuneration from organisations that may gain or lose financially; patents or patent applications whose value may be affected by publication.

Researchers are not forced to supply such information, and if they decide against disclosure Nature will simply publish a short note to this effect. Far from having sinister implications, researchers

Far from having sinister implications, researchers may simply not be permitted to disclose their collaborators

may simply not be permitted to disclose their collaborators and this currently prevents journals from enforcing these policies. 'Many research contracts between academic institutes and industry contain clauses that forbid publicly naming the industrial partner,' Ivo Feußner, a researcher at the IPK Gatersleben in Germany, who holds many research contracts with companies, explained. 'European companies are often much more conservative in this respect than their American competitors.' If a researcher responds positively to Nature's request, the reader will be informed via a short statement in the manuscript and directed to more detailed information on the Internet. 'Such a statement might be quite long,' Campbell explained. 'We therefore prefer to put this information on the Internet.'

To ensure that the review process remains fair, Nature reviewers will first judge the paper on a scientific basis. Only once the paper has been recommended for publication will the authors be asked to disclose their interests. Iain Mattaj, Editor of The EMBO Journal, is somewhat surprised by this: 'I do not believe that a reviewer will be negatively influenced if he receives information that the researchers were supported by industry.' And by asking for the information after the review process, Nature believes it is allowing the reader to make his or her own judgement. According to Campbell, it was a fairly long process that put this new policy into place. The idea initially formed after he had been consulted by the British authorities concerning the regulation of biotechnical research in Britain. 'I was surprised about the influence some groups wanted to exert on this decision,' Campbell commented. Mattaj also believes that statements about conflict of interest are logical but he does not consider them essential. While he speculated that other journals reporting on basic research might follow the same route, he said it was not his decision alone to impose this at The EMBO Journal. 'The discussions on this topic with regard to The EMBO Journal and EMBO reports are ongoing,' he said.

Medical journals have always been prominent among those that request a declaration of potential conflicts of interest. 'We have had disclosure policies for at least a decade,' Catherine DeAngelis, Editor of The Journal of the American Medical Association (JAMA), said. 'We reinforced them in July 2001 and in September, the top five American medical journals and others joined a common policy on declaring conflicts of interest.' Given that millions of dollars and people's lives might be at stake, such

universities and academic scientific institutes that obtain funding from private or industrial resources will grow continuously. This will lead to a state where research will not be discriminated against solely on the basis of where the funding comes from.'

However, putting the emphasis so firmly on personal financial interests could be misplaced since this is only one of many potential sources of bias in the prevailing publish-or-perish atmosphere of science. 'Not only pressure from industry might influence published data,' Mattaj added. 'Today researchers have a lot of other pressures. Their published results have a strong influence on their career and the possibility to find a [new] job.' Feußner supports this opinion. 'Many researchers who publish in the socalled first class journals these days have a connection to industry in one or the other way. We have to admit that there has been a change of values in science. We not only conduct research because

Given that millions of dollars and people's lives might be at stake, medical journals are understandably sensitised to the influence that drug companies and patient groups can exert

journals are understandably sensitised to the influence that drug companies and patient groups can exert. A study published in JAMA in 1999 found that privately funded studies were eight times more likely to find a drug effective than those conducted independently.

But Campbell remains convinced that the vast majority of researchers publish their results according to good practice. 'There are some hints that there have been problems in some medical journals in the past. In general, however, I think that scientific literature is honest to a high degree.' Mattaj agreed: 'I do not believe that the source of the funding in most cases will influence the interpretation of the data. Nevertheless, there have been cases in the past where the interpretation of data has been influenced by financial interests. An example for this are some research findings that would have affected the cigarette industry.'

Some scientists argue that a conflict of interest statement could lead to discrimination and that privately funded research will automatically be dismissed as biased. Campbell, however, does not see this as a problem: 'The number of researchers at we are curious and want to gain knowledge. Results have become a product that can be sold.' And industry is not the sole consumer. 'Especially public and governmental funding bodies are interested that the results of projects are published in first-class journals,' Feußner said. 'Companies are often more interested to have the results published in journals that are read by their customers.' Such journals are often quite different from the first-class

\section{Some scientists argue that a conflict of interest statement could lead to discrimination and automatically label their work as biased}

journals favoured by public funding bodies, leading to an alternative conflict of interest: only those who have good research results and publish them in wellknown journals will have continuous access to public money. 'I therefore think that only giving the industrial affiliations in a statement is insufficient. It would be better to make it a condition that all 
sources of money are named in the acknowledgements,' Feußner concluded.

Not only researchers but also referees and editors may face conflicts of interest, in which case journals such as Nature ask the referees not to review a paper. These may not necessarily be financial interests; for example, a paper might be rejected by a competitor to safeguard her or his own interests. 'Unfortunately, the editors hear from cases like that often too late,'
Campbell said. 'In general, however, the peer-review system functions astonishingly well.' The Nature publishing group also has a policy for their editors and staff to avoid conflicts of interest.

Disclosure is an ethical decision to be taken by an individual, but if the scientific community resists this transparency, it could not only be harmful to research but may also reduce the already shaken trust the public has in science as a whole.
'Anything published that has an impact on what the public believes should have a mechanism in place that ensures it is obvious where the information and the funding for the study comes from,' $J A M A^{\prime}$ s DeAngelis said.

\section{Ellen Peerenboom}

DOI: 10.1093/embo-reports/kvf018

\title{
From genomes to cures-a long way to go
}

\author{
More than a year after the publication of the first draft of the human genome, scientists took \\ stock of its implications for science and society
}

The publication of the human genome caused quite a stir. US President of the time Bill Clinton and Prime Minister Tony Blair of Britain both lauded the deciphering of the 'book of life', and the mediaas well as many scientists-never tired of stating that a new era in medicine had dawned.

Since the dust has now settled, a degree of sobriety has replaced the initial euphoria. This more realistic attitude was evident at the Science \& Society Conference 'From genomes to cures' that was jointly organised by EMBO and EMBL last November in Heidelberg, and which took stock of the promises, expectations, fears and drawbacks of sequencing the human genome. 'The information provides a new tool for science and medicine,' Samuel Broder, Senior Vice President of Celera Genomics in Rockville, MD, said in the opening talk. And the implementation of

The implementation of this new information, rather than its creation, will be the true revolutionary breakthrough

this tool, rather than its creation, will be the true revolutionary breakthrough. As the role of specific genes in any disease can now potentially be deciphered 'in ways that you wouldn't be thinking of in the realm of molecular biology, the use of this information will form the basis of biomedical research in the future, Broder

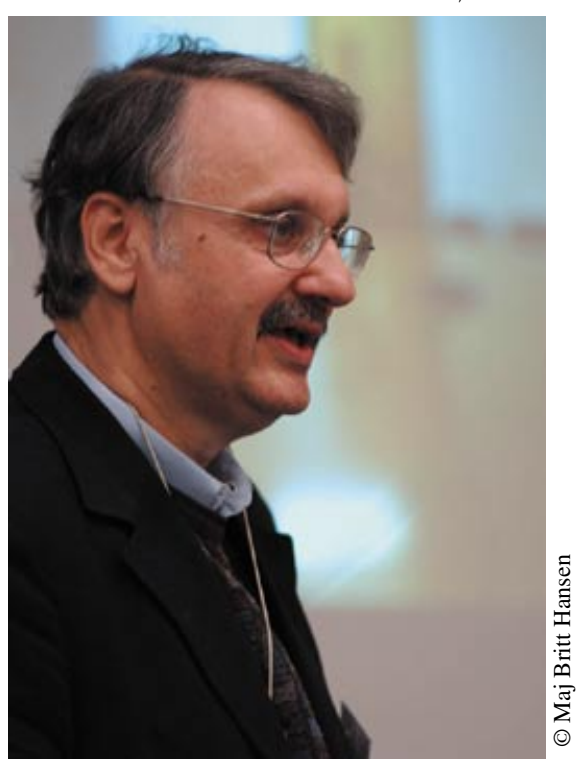

Samuel Broder: 'We have challenges of almost transcendental difficulty to overcome.'

said.

Indeed, the tasks ahead for medicine are numerous. Broder showed a collage of diseases caused by microbes, parasites and their vectors-most commonly occurring in the developing world-that was a clear reminder of the problems still unsolved. It is up to science to provide the tools to fight these 'agents of suffering and pain', as Broder called them. Turning to developed countries, he commented, 'I think there has been progress but we need to do better in this world where cancer is our target.' Broder also showed a slide of a patient suffering from ataxia telangiectasia, a neurodegenerative disease caused by the modification of a single nucleotide, and said, 'there is no technology available today [...] that can promise to correct this single nucleotide exchange. [...] We have challenges of almost transcendental difficulty to overcome.'

And the challenges are not only scientific-the public are still wary of the biomedical revolution. Frank Burnet of the UK Biochemical Society presented surveys from European countries illustrating that public anxieties about cloning, cynicism about the ambiguous role of drug companies and distrust in regulators persist. On the other hand, $90 \%$ of those

Researchers have a
responsibility not only to
keep the promises about
new cures, but also to be
truthful about the real
potential of their work

polled in the UK think that genetics should be used for better diagnosis and new cures to fight diseases. 'We are not talking about the public; we are talking 